\title{
EMPREGO DO ÓLEO RESIDUAL DE FRITURA NA PRODUÇÃO DE BIODIESEL
}

\author{
D. A. SILVEIRA ${ }^{1}$, G. E. G. VIEIRA ${ }^{2}$ \\ ${ }^{1}$ Centro de Tecnologia de Edificações \\ ${ }^{2}$ Universidade Federal do Tocantins \\ E-mail para contato: dsilveira@cte.com.br
}

\begin{abstract}
RESUMO - Óleos vegetais são produtos naturais formados principalmente por triglicerídeos e são utilizados principalmente na culinária e na produção de biocombustível. Atualmente verifica-se uma grande utilização dos óleos vegetais para a fritura de alimentos por imersão, sendo gerado consequentemente um grande volume de óleo residual. No Brasil se produz aproximadamente quatro bilhões de litros de óleo de fritura por ano. Frente à problemática do aumento desse resíduo deu-se a necessidade da sua reciclagem sendo a produção de biodiesel um dos principais alvos de interesse. A produção de biodiesel de óleo de fritura traz muitos benefícios para o ambiente e para a sociedade, principalmente em relação à minimização da poluição do ar e da poluição hídrica. Várias cidades brasileiras utilizam o óleo residual de fritura para produzirem diferentes compostos, como: sabão, cola, tinta, massa de vidraceiro e principalmente biodiesel. No processo de fritura as propriedades térmicas e fisicoquímicas do óleo vegetal são alteradas podendo afetar a produção do biocombustível. O biodiesel produzido através de óleo residual de fritura mostra-se muito importante, pois tais óleos já foram utilizados na alimentação e agora terão uma destinação que agrega valor. Desta forma o presente trabalho teve por objetivo realizar uma abordagem a respeito da utilização de óleo residual de fritura na produção de biodiesel.
\end{abstract}

\section{INTRODUÇÃO}

Os óleos vegetais são produtos naturais, insolúveis em água e solúveis em solventes orgânicos, constituídos principalmente por triglicerídeos. Possuem uma grande variedade de aplicações, porém a utilização na culinária e na produção de biocombustível são as que mais se destacam no cenário nacional e internacional. (Wust, 2004; Reda, 2004; Silveira, 2009).

Atualmente verifica-se um grande uso de óleo vegetal para fritura de alimentos. Em alguns estabelecimentos comerciais podem ser encontradas fritadeiras com capacidades que variam de 15 a 350 litros (1) de óleo e em indústrias podem chegar a 1000 litros. O tempo de utilização também varia de estabelecimento para estabelecimento, principalmente pela falta de legislação que determine a troca do óleo usado (Pasqualetto e Barbosa, 2008).

Diante da necessidade de reciclar alguns tipos de resíduos, da preocupação com o aquecimento 


\section{9 a 22 de outubro de 2014 \\ Florianópolis/SC}

global do planeta e da decorrente necessidade de diminuir os níveis de dióxido de carbono $\left(\mathrm{CO}_{2}\right)$ na atmosfera, tudo isso se tornou mais uma motivação importante para as pesquisas sobre combustíveis alternativos. Sendo assim, o óleo residual de fritura vem contribuir como fonte alternativa e abundante para produção de biocombustível (Santos et al, 2007; Miranda, 2007).

No Brasil estima-se que sejam produzidos quatro bilhões litros de óleo de fritura por ano, sendo que dois bilhões são descartados. A reciclagem desses resíduos vem ganhando espaço cada vez maior. Algumas cidades brasileiras, como Ribeirão Preto-SP, Curitiba-PR, ABC Paulista, Florianópolis-SC e Porto Alegre-RS, estão utilizando o óleo residual de fritura para produção de vários produtos. Porém, a disposição em aterros sanitários e esgotos domésticos é prática comum (Wust, 2004; Alberici e Pontes, 2004; Lima et al, 2007; Fernandes et al, 2008).

A utilização dos óleos residuais provenientes dos processos de fritura mostra-se ainda mais atraente para a produção de biodiesel, uma vez que já foram utilizados na alimentação e agora terão uma destinação que agrega valor, não sendo mais considerado como um resíduo (Pasqualetto e Barbosa, 2008).

Desta forma, o presente trabalho tem por objetivo discutir o emprego do óleo residual de fritura na produção de biodiesel, sendo que a metodologia utilizada para a realização do trabalho consistiu em uma revisão de literatura fundamentada em dissertações, trabalhos de conclusão de curso, revistas, artigos, sites entre outros.

\section{DESENVOLVIMENTO}

\section{1. Óleos Vegetais}

Os óleos são substâncias líquidas à temperatura ambiente, por possuírem de uma a quatro insaturações (ligações duplas na cadeia carbônica) enquanto que as gorduras caracterizam-se como substâncias sólidas devido a sua constituição em ácidos graxos saturados. São constituídos principalmente, por triglicerídeos ou triacilgliceróis, resultantes da combinação entre três moléculas de ácidos graxos e uma molécula de glicerol. Além de triglicerídeos, os óleos contêm vários componentes em menor proporção, como mono e diglicerídeos (importantes como emulsionantes); tocoferol (importante antioxidante); proteínas, esteróis, vitaminas e ácidos graxos livres (Wust, 2004; Reda, 2004; Reda e Carneiro, 2007).

Os ácidos graxos são ácidos carboxílicos de cadeia longa, geralmente possuem de oito a 24 átomos de carbonos. Quando saturados possuem apenas ligações simples entre os carbonos e possuem pouca reatividade química. Já os ácidos graxos insaturados, contêm uma ou mais ligações duplas no seu esqueleto carbônico; são mais reativos e mais suscetíveis a termo-oxidação (Costa Neto et al, 2000; Reda e Carneiro, 2007).

\subsection{Principais Utilizações dos Óleos Vegetais}

De acordo com Reda e Carneiro (2007) cerca de dois terços dos óleos vegetais são usados em 


\section{9 a 22 de outubro de 2014 \\ Florianópolis/SC}

produtos alimentícios fazendo parte da dieta humana. A população em geral faz uso de óleos vegetais para a fritura de alimentos por imersão.

A fritura por imersão é um processo que os alimentos são submetidos a temperaturas elevadas em torno de $180^{\circ} \mathrm{C}$ a $200^{\circ} \mathrm{C}$ em contato direto com ar atmosférico. Vários são os óleos vegetais que podem ser utilizados na alimentação, como o óleo de soja, de dendê, de girassol entre outros (Wust, 2004).

Segundo Parente (2003) todos os óleos vegetais, enquadrados na categoria de óleos fixos ou triglicerídeos, podem ser transformados em biodiesel, através da reação de transesterificação, a qual o óleo vegetal reage com álcool (metílico ou etílico) formando ésteres (metílicos ou etílicos) e glicerol. O biodiesel é um combustível renovável, biodegradável e ambientalmente correto, similar ao óleo diesel de petróleo.

A reação de transesterificação é o processo mais utilizado atualmente para produção de biodiesel e pode empregar diversos tipos de álcoois, preferencialmente os de baixo peso molecular como: metanol, etanol, propanol, butanol, sendo os mais estudados os álcoois metílico e etílico. O biodiesel também pode ser obtido por outros processos como a esterificação, pirólise ou craqueamento térmico, e microemulsificação (Castellenelli, 2008; Rosa, 2010).

Podem constituir matéria prima para a produção de biodiesel os óleos das seguintes espécies vegetais: grão de soja, grão de amendoim, polpa do dendê, amêndoa do coco de dendê, amêndoa do coco da praia, caroço de algodão, amêndoa do coco de babaçu, semente de girassol, baga de mamona, semente de colza, entre muitos outros vegetais em forma de sementes, amêndoas ou polpas. Atualmente a matéria-prima mais utilizada para a produção do biodiesel no Brasil é o óleo de soja extraído de seu grão (Parente, 2003; Cardoso, 2008).

Uma tendência atual é que as empresas produtoras de biodiesel sejam integradas, ou seja, plantam ou comercializam a matéria-prima, esmagam o grão para produzir o óleo vegetal e produzem o biodiesel. No caso estas empresas têm a opção de vender o grão, vender o óleo vegetal ou vender o biodiesel, normalmente, optam por vender os produtos que tiverem melhores margens num determinado período. Essas empresas são mais competitivas e mais eficientes na comercialização do biodiesel, conseguindo se apropriar de melhores margens do que as não integradas (Gazzoni, 2010).

\subsection{Reciclagem dos Óleos de Fritura para Fins ou Aplicações Variadas}

A reciclagem de resíduos gordurosos vem ganhando espaço cada vez maior, não simplesmente porque os resíduos representam "matérias primas" de baixo custo, mas, principalmente, porque os efeitos da degradação ambiental decorrente de atividades industriais e urbanas estão atingindo níveis cada vez mais alarmantes (Fernandes et al, 2008).

Alguns trabalhos têm sido realizados com o objetivo de se dar uma destinação adequada para tais resíduos, que podem ser utilizados para a produção de sabão, cola, tinta, massa de vidraceiro, ração animal, produção de biocombustível, entre outros. Porém, a disposição em aterros sanitários e 


\section{9 a 22 de outubro de 2014 \\ Florianópolis/SC}

esgotos domésticos é prática comum (Wust, 2004; Alberici e Pontes, 2004; Lima et al, 2007).

Nos últimos anos projetos de reciclagem têm sido desenvolvidos no Brasil, dentre eles destacam-se o aproveitamento dos óleos vegetais usados nos processos de fritura de alimentos por imersão como nos municípios de Ribeirão Preto-SP, Curitiba-PR, ABC Paulista, Florianópolis-SC e Porto Alegre-RS, que são alguns exemplos de projetos bem sucedidos (Fernandes et al, 2008).

Segundo Instituto Akatu (2007), em Ribeirão Preto e região, no interior paulista, o óleo de cozinha é reciclado. O projeto "Biodiesel em casa e nas escolas", desenvolvido pelo Laboratório de Desenvolvimento de Tecnologias Limpas do Departamento de Química da USP de Ribeirão Preto, visa produzir biodiesel por meio do óleo usado nas frituras e tem parceria com alguns supermercados da cidade de Ribeirão Preto e com algumas escolas da rede pública de ensino. Atualmente o projeto consegue captar cerca de 20 mil litros de óleo de fritura por mês, que seriam descartados de forma inadequada. Além de Ribeirão, as cidades da região que têm escolas cadastradas no projeto são Sertãozinho, São Carlos, Araraquara, Batatais e Pradópolis.

Segundo o Ambiente Brasil (2008), no final do ano de 2008 doze ônibus articulados, iriam começar a circular com biodiesel proveniente de óleo de fritura na cidade de Curitiba no estado do Paraná. Tal iniciativa foi tema da segunda Reunião do Grupo de Trabalho de Avaliação das Mudanças Climáticas. Segundo a companhia responsável pelos doze ônibus, estes iriam demandar por dia de dois mil litros de óleo de fritura. Isto não representando problema, pois a oferta deste, a princípio um resíduo de alto potencial poluente, era estimada em 800 mil litros por mês, portanto suficiente para essa investida inicial.

Outro exemplo da utilização de óleo de fritura é o trabalho desenvolvido pela organização não governamental (ONG) Ação Triângulo, OSCIP (Organização da Sociedade Civil de Interesse Público) com sede na cidade paulista de Santo André. Todos os meses, seus 60 agentes socioambientais visitam 60 mil residências em diversos bairros de cidades do ABC paulista (que engloba as cidades de Santo André, São Bernardo e São Caetano) para recolher óleo de cozinha. São recolhidas cinco toneladas de óleo de fritura por mês para produzir sabões em pedra e sabonetes, que posteriormente são vendidos para custear ações ambientais, sociais e de consumo consciente desenvolvidas pela entidade (Instituto Akatu, 2007).

Segundo a Associação Floripamanhã (2007), o óleo de cozinha é reaproveitado há 20 anos na cidade de Florianópolis no estado de Santa Catarina. Tal reaproveitamento iniciou-se após o vazamento de esgoto na Avenida das Rendeiras em 1988, quando foi criado o projeto ambiental conhecido com ReÓleo. Tal projeto faz a reciclagem do óleo de fritura transformando em sabão, massa de vidro e biodiesel. O programa foi criado pela Associação Comercial e Industrial de Florianópolis (Acif) e em duas décadas mais de um milhão de litros de óleo deixaram de ser despejados de forma inadequada em bueiros e pias.

Segundo Alberici e Pontes (2004), metade das 120 toneladas de óleo comestível usado na grande Porto Alegre é reciclada e transformada em cola e tinta para uso industrial. Segundo os autores, a empresa Recolhimento de Óleos (Recolt), responsável pela coleta e o processamento do 


\section{9 a 22 de outubro de 2014 \\ Florianópolis/SC}

óleo, "o preço pago pelo óleo de cozinha usado pelas indústrias de reciclagem (não mais que R $\$ 0,04$ o quilo) não é atraente e a armazenagem do líquido significa um trabalho a mais para o empresário e para a dona de casa". Neste sentido, a questão se resume na conscientização de comerciantes e da população em geral da importância em preservar o meio ambiente.

Ainda segundo esse autor se produz também o biodiesel, combustível limpo, a partir de óleo comestível usado, projeto desenvolvido pela COPPE (Coordenação de Programas de Pós-Graduação em Engenharia da Universidade Federal do Rio de Janeiro). O McDonald's, uma rede de fast food, doa mensalmente para processamento cerca de 25 mil litros de óleo de fritura utilizado em 40 restaurantes próprios da rede na cidade do Rio de Janeiro. O óleo é utilizado para a fritura de batatas, frango, peixe empanados e tortas doces (Alberici e Pontes, 2004).

\subsection{Benefícios da Utilização de Óleo de Fritura para Produção de Biodiesel}

A utilização de óleo de fritura para produção de biodiesel traz inúmeros benefícios para o ambiente e para a sociedade.

Diminui vários problemas relacionados à poluição ambiental, pois quando esse resíduo é descartado na rede de esgoto a sua decomposição emite metano, um dos principais gases do efeito estufa que contribui para o aquecimento da Terra. Quando lançados nos corpos hídricos diminuem a área de contato entre a superfície da água e o ar atmosférico impedindo a transferência do oxigênio, causando alteração no ecossistema aquático (Pasqualetto e Barbosa, 2008; Fernandes et al, 2008).

A implantação deste combustível na matriz energética também reduz drasticamente a emissão de outros gases poluentes, como o dióxido de carbono, além de eliminar completamente o enxofre, um dos principais vilões da chuva ácida. Outro benefício é que o biodiesel possui como qualidade, uma excelente lubricidade, ou seja, a capacidade de um fluído de diminuir o atrito entre duas superfícies. Fazendo com que os componentes do veículo aumentem sua durabilidade (Pasqualetto e Barbosa, 2008; Fernandes et al, 2008).

De acordo com Fernandes et al. (2008), com relação à biodegradabilidade, o biodiesel mostrou resultados bem satisfatórios. Em exames feitos pelos métodos de evolução de dióxido de carbono, cromatografia a gás e de germinação de sementes, várias amostras de biodiesel, apresentaram fácil biodegrabilidade em ambientes aquáticos e terrestres.

De acordo com Costa Neto et al. (2000) no aspecto econômico o biodiesel se torna competitivo, pois complementa todas as novas tecnologias do diesel com desempenho similar e sem a exigência da instalação de uma infraestrutura ou política de treinamento.

A utilização de biodiesel de óleo de fritura é economicamente atraente, pois permite a valorização de subprodutos de atividades agroindustriais, aumenta a arrecadação regional do Imposto sobre Circulação de Mercadorias e Prestação de Serviços (ICMS), aumenta a fixação do homem no campo e de investimentos complementares em atividades rurais (Costa Neto et al, 2000).

O processo de produção de biodiesel com óleo de fritura também gera o glicerol, uma 


\section{9 a 22 de outubro de 2014 \\ Florianópolis/SC}

substância empregada nas indústrias e com usos farmacêuticos, alimentícios, perfumaria, plástico e muitos outros (Pasqualetto e Barbosa, 2008; Cardoso, 2008). Todos esses benefícios se voltam para a melhoria da qualidade de vida das pessoas, evidenciando assim a importância de uma destinação correta para esse resíduo (Silveira, 2009).

\subsection{Produção de Biocombustíveis versus Produção de Alimentos}

Para explicar a alta do preço de alimentos no mundo, o argumento mais comum é jogar a culpa na produção de biocombustíveis. Ou seja, a oferta de comida teria diminuído em decorrência da redução de áreas agriculturáveis para o setor, levando a um aumento de produtos alimentícios (Agroambiente, 2008).

No entanto, vários estudos mostraram que essa explicação está equivocada, pois os dois setores convivem perfeitamente, sem que um afete a produção do outro. Um exemplo é o estudo feito na Faculdade de Agronomia e Medicina Veterinária da Universidade de Brasília (UnB), que mostrou estatisticamente alta nas safras das principais culturas de alimentos. De acordo com a economista Dora Isabel Murillo Hernández, autora da pesquisa, a produtividade das culturas de milho, arroz e feijão cresceram entre os anos de 1995 e 2006. E o mais surpreendente: a produção agroalimentar aumentou sem precisar de novas terras. O petróleo é o principal responsável pelo aumento dos preços dos alimentos, pois encarece o transporte e os insumos utilizados na produção (Agroambiente, 2008). (Agroambiente, 2008).

A produção de milho aumentou de 36,2 milhões de toneladas para 42,6 milhões em uma década, a produtividade cresceu de 2,5 toneladas por hectare (t/ha) para 3,2 t/ha, uma evolução de $27 \%$. O espaço ocupado por essa lavoura, que era de 14,1 milhões de hectares, passou para 12,9 milhões de hectares. Em relação ao arroz, foram colhidos 11,2 milhões de toneladas em 1995 e 11,5 milhões em 2006, com aumento na produtividade, que era de 2,5 t/ha e foi para 3,8 t/ha. Esses fatores fizeram com que essas lavouras liberassem mais de $25 \%$ da área anteriormente utilizada, passando de 4,4 milhões de hectares para três milhões de hectares (Agrosoft, 2008).

Segundo o professor José Tadeu Jorge, ex-reitor da Universidade Estadual de Campinas (Unicamp), em sua palestra durante a Conferência "Produção de Alimentos vs. Produção de Biocombustíveis", o responsável pelo aumento dos preços dos alimentos é o crescimento da demanda internacional e não a diminuição da produção deles para suposta produção de biocombustíveis. Ele também apontou que não foram somente os alimentos que subiram de preço, mas outras commodities, como o petróleo e cobre (Universia, 2008).

De acordo com a Ação Brasileira pela Nutrição e Direitos Humanos - ABRANDH, atualmente o mundo produz alimentos em quantidade suficiente para todos. $\mathrm{O}$ que ocorre é que muitos não têm acesso a eles e há um enorme desperdício. No Brasil, segundo o Instituto Brasileiro de Geografia e Estatística (IBGE), em 1999, o país desperdiçou 39 milhões de toneladas de alimentos, quantidade suficiente para alimentar 19 milhões de pessoas (Abrandh, 2008). Diante disso, os óleos vegetais residuais de processos de frituras de alimentos mostram-se ainda mais atraentes para a produção de biodiesel, na medida em que aproveita o óleo vegetal como combustível após a sua utilização na 
cadeia alimentar, resultando assim num segundo uso, ou mesmo uma destinação alternativa a um resíduo da produção de alimentos (Pasqualeto e Barbosa, 2008).

\section{CONCLUSÃO}

A reciclagem dos óleos residuais utilizados na fritura de alimentos possibilita a produção de variados compostos, servindo então como uma importante matéria prima. Vários são os fatores positivos quando se utiliza o óleo de fritura para produção de algum tipo de material. Tanto melhorias para o ambiente como para sociedade podem ser facilmente visualizados, como: redução da emissões de gases do efeito estufa, além de fomentar a geração de empregos no setor agrícola, através de postos de trabalho e investimentos de novas indústrias. Por isso a importância da conscientização da população para coleta e reciclagem deste produto, dando uma destinação correta para tal. Em relação à produção de biodiesel utilizando óleo de fritura, esta alternativa torna-se ainda mais atraente pelo fato de se usar um subproduto da alimentação, que seria descartado na maioria das vezes de forma imprópria, e agora sendo utilizada para a produção de um combustível, fortalecendo ainda mais o processo de reciclagem.

\section{REFERÊNCIAS}

ABRANDH. A crise mundial de alimentos viola o direito humano à alimentação. Brasília, DF, jun., 2008. 8p.

AGROAMBIENTE. Biocombustível não atinge a produção de alimentos. 2008.

AGROSOFT. Estudo da Unb avalia que biocombustível não ameaça alimentos. 2008.

ALBERICI, R. M.; PONTES, F. F. F. Reciclagem de Óleo Comestível Usado Através da Fabricação de Sabão. Eng. Amb., Espírito Santo do Pinhal, vol. 1, n¹, jan./dez., 2004. P. 073-076.

AMBIENTE BRASIL. Doze ônibus movidos a biodiesel de óleo de fritura vão rodar experimentalmente em Curitiba (PR). 2008.

ASSOCIAÇÃO FLORIPAMANHÃ. Ampliada reciclagem de óleo de cozinha. 2007.

CARDOSO, L. M. Estudo dos processos de obtenção de biodiesel. 2008, 39p. Trabalho de Conclusão de Curso (Bacharel em Engenharia Ambiental). Universidade Federal do Tocantins, Palmas, TO.

CASTELLANELLI, C. A. Estudo da viabilidade de produção do biodiesel, obtido através do óleo de fritura usado, na cidade de Santa Maria - RS. 2008. 111p. Dissertação (Mestrado em Engenharia de Produção). Universidade Federal de Santa Maria, Santa Maria, RS, 2008.

COSTA NETO, P. R.; ROSSI, L. F. S.; ZAGONEL, G. F.; RAMOS, L. Z. P. Produção de Biocombustível alternativo ao óleo diesel através da transesterificação de óleo de soja usado em frituras. Quím. Nov. 2000, vol. 23, no. 4, pp. 531-537. ISSN 0100-4042.

FERNANDES, R. K. M.; PINTO, J. M. B.; MEDEIROS, O. M. de.; PEREIRA, C. de A. Biodiesel a partir de óleo residual de fritura: alternativa energética e desenvolvimento 
sócio-ambiental. XXVIII Encontro Nacional de Engenharia de Produção. Rio de Janeiro, RJ, 13 a 16 de outubro, 2008; 10p.

GAZZONI, D. Biodiesel: mrecado atual e perspectivas. 2010.

INSTITUTO AKATU. Sabão é Alternativa de Reaproveitamento do Óleo de cozinha. 2007.

LIMA, M. V. S.; NUNES, R. C. da R.; ARAÚJO B. Q.; FIGUEIREDO, F. C.; SANTOS JUNIOR, J. R. dos. Síntese de ésteres (biodiesel) a partir de óleo de fritura com metanol e etanol. In: XVI Seminário de Iniciação Científica da UFPI, 2007, Teresina - PI, 2007.

MIRANDA, R. A. de. Biodiesel: obtenção a partir de óleos residuais utilizados na cocção de alimentos. In: II Congresso da Rede Brasileira de Tecnologia do Biodiesel ABIPTI. Brasília, DF, 27 a 29 de novembro, 2007, 5p.

PARENTE, E. J. de S. Biodiesel - Uma aventura tecnológica num país engraçado. Editora Unigráfica: Fortaleza-CE. 2003.

PASQUALETTO, A.; BARBOSA, G. N. Aproveitamento do óleo residual de fritura na produção de biodiesel. In. XXXI Congresso Interamericano AIDIS. Santiago, Chile, 12 a 15 de outubro, 2008, 8p.

REDA, S. Y. CARNEIRO, P. I. B. Óleos e Gorduras: Aplicações e Implicações. Rev. Anal. fevereiro/março, 2007, N'27. 60-67p.

REDA, S. Y. Estudo Comparativo de Óleos Vegetais Submetidos a Estresse Térmico. 2004, 153 p. Dissertação (Mestrado em Engenharia de Alimentos). Universidade Estadual de Ponta Grossa, PR.

ROSA, C. D. Produção enzimática de biodiesel em modo contínuo em meio pressurizado. 2009. 134p. Tese (Doutorado em Engenharia de Alimentos). Universidade Federal de Santa Catarina, Florianópolis, SC, 2009.

SANTOS, R. B. dos.; SERRATE, J. W.; CALIMAN, L. B.; LACERDA Jr, V.; CASTRO, E. V. R. Avaliação do uso de óleo residual usado em fritura para a produção de biodiesel e estudo da transesterificação de óleo de soja com alcoóis de cadeia de até quatro carbonos. In: II Congresso da Rede Brasileira de Tecnologia do Biodiesel ABIPTI. Brasília, DF, 27 a 29 de novembro, 2007, 6p.

SILVEIRA, D. A. Processo de purificação de óleo de soja residual utilizado em fritura para reaproveitamento industrial. 2009, 45 p. Trabalho de Conclusão de Curso (Bacharel em Engenharia Ambiental). Universidade Federal do Tocantins, Palmas, TO.

UNIVERSIA. Produção de Alimentos X Produção de Biocombustíveis. 2008.

WUST, E. Estudo da viabilidade técnico-científica da produção de biodiesel a partir de Resíduos gordurosos. 2004, 113p. Dissertação (Mestrado em Engenharia Ambiental). Universidade Regional de Blumenau, SC. 